\section{Single Gene Inactivation with Implications to Diabetes and Multiple Organ Dysfunction Syndrome}

\section{Abstract}

Nutritional and environmental epigenetics are involved with the repression of anti-aging genes that are linked to the chronic disease epidemic. Unhealthy diets inactivate the calorie sensitive gene Sirtuin 1 (Sirt 1) involved in epigenetic processes that promote immune system alterations, mitochondrial apoptosis, Non-alcoholic Fatty Liver Disease (NAFLD), diabetes and Nitric Oxide (NO) modification with relevance to core body temperature involved with appetite regulation, glucose homeostasis and hepatic xenobiotic metabolism. The interplay between NO and epigenetics has attracted interest with relevance to autoimmune disease and mitophagy that has become of critical concern to diabetes and the development of MODS. Future research involved with nutritional research and the maintenance of Sirt 1 transcriptional control is critical to the prevention of MODS that is linked to the immune system and insulin resistance. In the developing world bacterial lipopolysaccharides a critical repressor of Sirt 1 is now involved with NAFLD and various organ diseases relevant to tissue accumulation of xenobiotics from various environments with relevance to MODS and the global chronic disease epidemic.

Keywords: Diet; Sirtuin 1; Suprachiasmatic nucleus; Circadian; Xenobiotic
Ian James Martins ${ }^{1-3 *}$

1 Centre of Excellence in Alzheimer's Disease Research and Care, School of Medical and Health Sciences, Edith Cowan University, Australia

2 School of Psychiatry and Clinical Neurosciences, The University of Western Australia, Nedlands, 6009, Australia

3 McCusker Alzheimer's Research Foundation, Hollywood Medical Centre, Nedlands, 6009, Australia

\section{*Corresponding author: Ian Martins \\ झ i.martins@ecu.edu.au}

Centre of Excellence in Alzheimer's Disease Research and Care, School of Medical and Health Sciences, Edith Cowan University, 270 Joondalup Drive, Joondalup, Western Australia 6027, Australia.

Tel: +61863042574

Citation: Martins IJ (2017) Single Gene Inactivation with Implications to Diabetes and Multiple Organ Dysfunction Syndrome. J Clin Epigenet. Vol. 3 No. 3:24

syndrome (MODS) [12-14]. These toxic compounds are involved in nuclear receptor dysfunction such as the nuclear receptor Sirtuin 1 (Sirt 1) [5] that determines the survival of man and various species with relevance to toxicity to mitochondria in neurons $[15,16]$ and cells in peripheral tissues [17-27].

\section{Sirt 1 Repression with Accelerated Brain Aging and Organ Disease}

The defective gene in various chronic diseases [28-38] is Sirt 1 a NAD(+)dependent class III histone deacetylase (HDAC) protein that targets transcription factors to adapt gene expression to metabolic activity, insulin resistance and inflammation. Interests in Sirt 1 have increased since it may override the effects of other anti-aging genes such as Klotho, p66Shc (longevity protein) and Fork head box proteins (FOXO1/FOXO3a) [8]. In adipose tissue gene expression profiles of Klotho, p66Shc (longevity protein) 


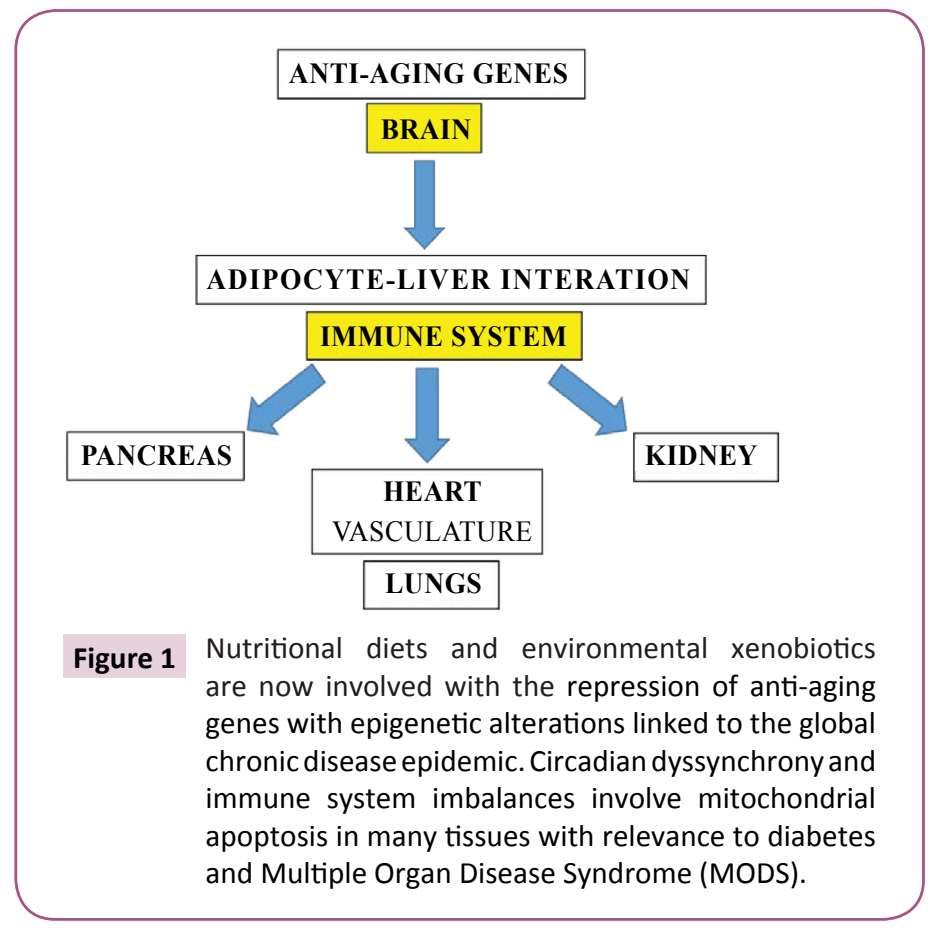

and Fork head box proteins (FOXO1/FOXO3a) have been completed and indicate down regulation of these genes are related to mitochondrial apoptosis, adipogenesis and adipocyte differentiation [29-38]. Sirt 1 is central to the down regulation of the other anti-aging genes via its role as a deacetylase of the transcription factor p53 [8]. Sirt 1/p53 dysregulation is important to mitochondrial apoptosis [4] and p53 interference has become a key defect in biology [39-42] with relevance to MODS and the diabetes epidemic.

The main types of brain cells are the glial cells (astrocytes, oligodendrocytes, and microglia) and the interaction of the glial cell referred to as the astrocyte with the neuron are essential to maintain neuron life span and prevent neurodegenerative disease [43]. Neurons in the brain with Sirt 1 repression may undergo early programmed cell death [44] with altered astrocyte neuron interactions that lead to accelerated brain aging [45]. Sirt 1 and its dysfunction in the brain involves the SCN and Sirt 1 repression inactivates the SCN that is involved with appetite regulation, body glucose control, circadian rhythm and hepatic xenobiotic metabolism $[5,46]$. Xenobiotics interfere with Sirt $1^{\prime}$ regulation of DNA repair $[47,48]$ and p53 transcriptional regulation [39-42] with relevance to interference with mitochondrial biogenesis $[4,49,50]$ and promotion of mitochondrial apoptosis in neurons with effects on synaptic plasticity [51-58].

Sirt 1 activation of the non amyloidogenic $\alpha$-secretase is involved in the processing of the amyloid precursor protein (APP) to reduce amyloid beta generation [59]. Sirt 1 dysregulation increased toxic amyloid beta formation associated with mitochondrial apoptosis [60]. SCN and its regulation of core body temperature [61] has become of major interest to species survival with Sirt 1 now regarded as the heat shock gene [62-64] with temperature regulation critical to Sirt 1 regulation of insulin resistance and xenobiotic metabolism $[5,65,66]$. Sirt 1 involvement in telomere maintenance maintains chromosome stability and its regulation of telomere length may be nullified by increased xenobiotics with telomere length shortening $[4,5,67,68]$.

Sirt 1 effects on p53 gene regulation supersede micro RNA (miRNAs) regulation of p53 [69-71] with relevance to their role in various chronic diseases [17-27]. MiRNAs such as miR-34a [72] and miR-122, miR-132 [73,74] inhibit Sirt 1 and may inactivate p53-miRNA interactions. Interference with cellular miRNA by diet, drugs and xenobiotics are now relevant to Sirt $1 / \mathrm{p} 53$ dysregulation and cell apoptosis. MiRNAs may regulate Sirt $1 / p 53$ regulation of nuclear receptors such as peroxisome proliferatoractivated receptor-gamma co-activator (PGC-1 alpha) and Pregnane $X$ Receptor (PXR) with interference with xenobiotic metabolism relevant to mitochondrial biogenesis $[4,5,75,76]$.

Other nuclear receptors such as peroxisome proliferatoractivated receptor gamma (PPAR gamma), PPAR alpha, beta/ delta, liver $\mathrm{X}$ receptors (LXR)/liver receptor homolog-1 (LRH-1) involved in energy, glucose, cholesterol, fatty acid metabolism are regulated by Sirt 1 with connections between hepatic nutrient and xenobiotic metabolism (PXR, CAR and xenobiotic sensing nuclear receptor) involved in the expression of cytochrome $p$ 450 (CYP 450) enzymes [5]. Increased levels of xenobiotics in the plasma and various tissues may lead to increased reactive oxygen species associated with low Sirt1 activity $[77,78]$ which is associated with chronic diseases in developing countries.

\section{SCN dysfunction in diabetes with relevance to MODS}

Insulin resistance and beta cell dysfunction has been associated with the development of MODS $[79,80]$. In Type 2 diabetes more than 150 genetic loci are associated with the development of diabetes and 50 candidate genes have shown to play a major part in the development of the disease [81]. These genes are involved in pancreatic $\beta$ cell function, insulin action and glucose metabolism in metabolic conditions. In Type 1 diabetes the HLA class genes have been associated with Type 1 diabetes with differences in haplotypes in ethnic groups such as Caucasians, African, Americans, Japanese and Chinese [46]. Sirt 1 regulation of the MODY gene via transcription factors hepatocyte nuclear factor 1 has been shown with evidence of genetic regulation of liver and pancreas in Type 1 diabetes [81]. Nutritional dysregulation of Sirt1 and the SCN may now involve Type 1 , Type 2 and Type 3 diabetes (Figure 2) [63,82] and induce MODS that involves accelerated organ diseases with hepatic xenobiotic metabolism (NAFLD) completely inhibited in these individuals. Sirt 1 repression induces mitophagy with the development of MODS and may supersede the connections between diabetic genes (Type 1 and 2) and their associated diseases (Figure 2). Sirt 1 plays an important role in the regulation fibroblast growth factor 21 [82-84] and the apelinergic pathway [85] with connections to brain insulin resistance (stroke, dementia, AD) [86]. In Type 2 diabetes the relevance of stress, anxiety and hyperphagia are associated with defective apelinergic pathways [85] and severity of diabetes (post-transcriptional defect) associated with Sirt 1-apelinergic system defects in mental disorders [87].

Dysregulated Sirt 1 on adipocyte differentiation and senescence involves gene expression and secretion of adiponectin with effects 
on the release of adipokines and cytokines that are implicated in NAFLD and chronic diseases [88-97]. Sirt 1 interactions with forkhead transcription factor 01 (FOXO1), C/EBP alpha may involve Klotho C/EBP alpha and peroxisome Proliferator-Activated Receptor (PPAR) interactions [98-103] important to mitochondrial function and adipocyte differentiation. Furthermore miR-122 and miR-132 [4] have been shown directly inhibit Sirt 1 and may interfere with adipose tissue adiponectin release. FGF21 binds to FGF receptor and beta koltho receptor complex [104-108] and activates adipose tissue Sirt 1/p53 with interactions with relevance to PGC1-alpha, peroxisome proliferator activated receptor gamma, FOXO 1 [109-111] and AMP activated protein kinase (AMPK) involved in adipocyte tissue transformation. FGF21 and Sirt 1 are essential for liver mitochondrial function (Figure 2) and regulate pancreas mitochondrial biogenesis and beta cell insulin secretion [112].

Sirt 1 effects on hepatic cholesterol metabolism and NAFLD are mediated via Sirt 1 and transcription factor C/EBP alpha that regulates the transcription of the apolipoprotein $B$ gene [113]. The protein kinase c-jun amino-terminal kinase 1 (JNK1) can phosphorylate Sirt 1 with phosphorylation of Sirt 1 important to p53 activation with relevance to NAFLD and the metabolic syndrome [46]. Sirt 1 and its connections to NAFLD may involve Brd4/p53 interactions with relevance to Brd 4-P-TEFb involvement in mitotic progression $[46,114]$. The control of the adipose tissue-liver crosstalk (gene expression) by the SCN is defective in diabetes (Type 3 ) and related to excess calorie consumption or core body temperature that overrides the Sirt 1 related SCN entrainment [61]. SCN defects are related to the peripheral circadian clock dyssynchrony [115] (adipose tissueliver cross talk) that determine Sirt 1 regulation of low adiponectin and melatonin levels involved in the metabolic syndrome, NAFLD and reverse cholesterol transport $[61,83,116]$ with relevance to diabetes and the severity of MODS (Figure 2)

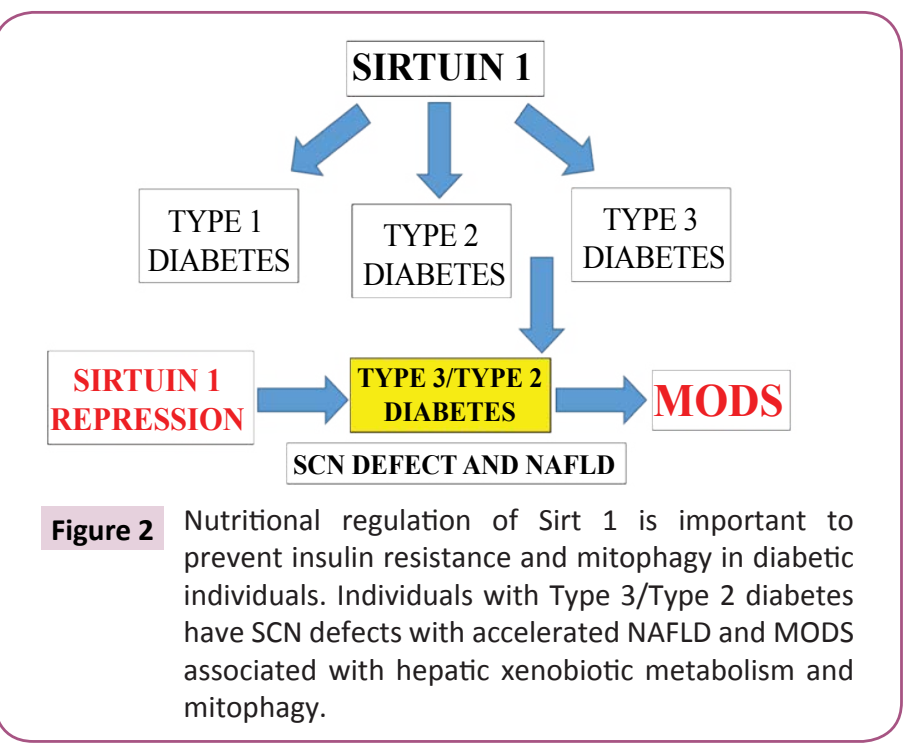

\section{Epigenetic Modifications Involve Nitric Oxide and Immune Dysregulation in Diabetes}

Induction of epigenetic alterations that determine brain dysfunction involve Nitric Oxide (NO) homeostasis and effect the adipose tissue-livercrosstalk with relevance to immune alterations that determine the survival of cells in various tissues. Diabetic individuals with defective $\mathrm{SCN}$ and brain-liver crosstalk involve immune imbalances as the primary cause of MODS. In Type 3/ Type 2 individual's reduced xenobiotic metabolism is associated with NAFLD and the induction of MODS connected to the immune system. Sirt 1/p53 transcriptional responses are involved in NO metabolism [ $85,117-119]$ and immunometabolism regulated by diet, drugs and the environment are critical to mitochondrial apoptosis and the induction of NAFLD in the developed world. Sirt 1 is connected to immunometabolism [9] and adipogenesis disorders with adipose tissue release of adipokines, inflammatory cytokines, heat shock proteins and natural killer cells relevant to mitophagy in diabetes and MODS. Sirt 1 is essential to maintain the SCN, NO homeostasis [85] and its dysfunction is critical to the defective circadian rhythm of heat shock proteins [60-63] with relation to cellular immune response $[9,120]$. Sirt 1 and its regulation of autoimmune disease is central to defective liver fat metabolism [9] with maintenance of Sirt 1 in adipose tissue and the liver of critical importance to MODS. Heat/cold stress inactivate the heat shock gene Sirt 1 [60-63] with NO dyshomeostasis, immune system imbalances connected to mitophagy (Figure 3) $[4,5,9]$. NO regulation of p53 [117-119] is important to epigenetic regulation and Sirt 1 post-transcriptional regulation by NO $[85,121-123]$ involves p53/miRNA $[4,124,125]$, anti-aging gene p66shc [126-128], klotho [129-131], FOXO 3a $[132,133]$, transcription factors PGC1 alpha $[132,134,135]$, PPAR [136-138], LXR-ABCA1 [139,140], AMPK signalling [85,141,142], HSP/body temperature regulation [143-146] and glucose homeostasis $[147,148]$. The importance of Sirt 1 and the immune response is now consistent with its interplay between $\mathrm{NO}$ and epigenetics $[149,150]$ with relevance to human health and disease (Figure 3). The role of NO and cytochrome p450 complex formation [151-153] has become relevant to cytochrome P450 expression in xenobiotic metabolism [5] with increased liver NO [85] implicated in the inactivation of Sirt1/PXR's control of xenobiotic metabolism $[4,5,154,155]$. Sirt 1 and its regulation of immunometabolism [9] are connected to xenobiotic metabolism with implications to MODS and xenobiotic induced immune alterations $[156,157]$. Xenobiotics may nullify Sirt 1 's role in NO homeostasis and vasodilation in the heart [85] with relevance to interference of therapeutic drugs for blood vessel dilation [158]. NO regulates calcium signalling in various cells [159-161] and in the SCN alterations in cell calcium is critical to circadian dyssynchrony [162].

Lifestyle factors with Nutritional interventions may reverse Global chronic disease Low calorie diets that upregulate Sirt 1 promote anti-aging gene therapy, miRNA function, transcriptional factor 


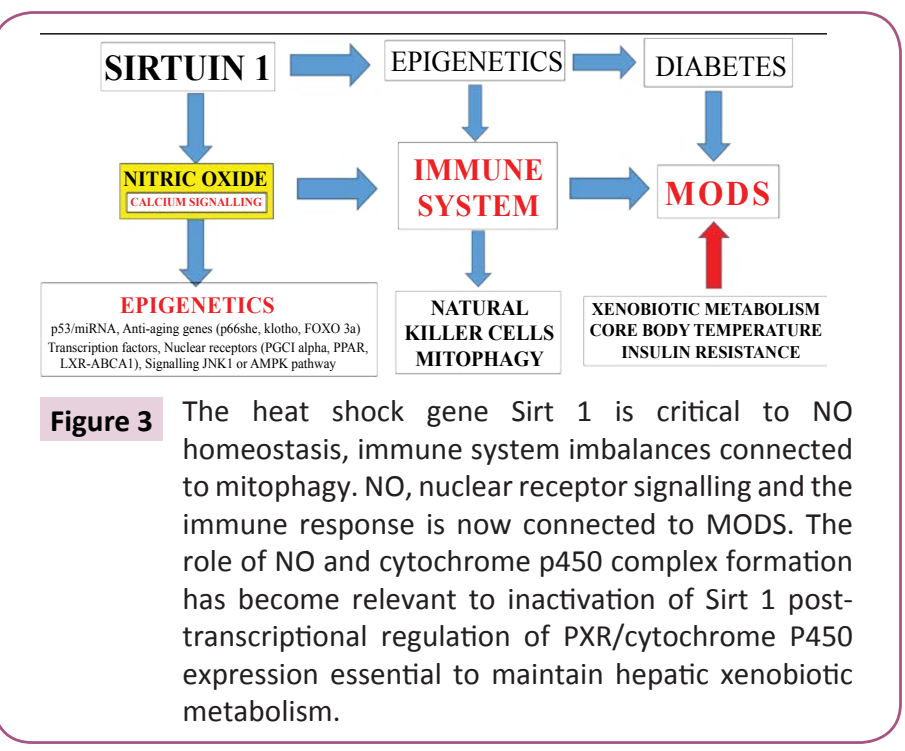

control and interactive nuclear receptor signalling in various cells and tissue with relevance to maintenance of immune response and prevention of autoimmune disease that may be connected to global chronic disease and the development of MODS (Figure 3). Bacterial LPS is involved with NAFLD and interference with hepatic xenobiotic metabolism is relevant to increased mitophagy and neurodegeneration. Nutritional diets with Sirt 1 activators [162] have become important to molecular and genetic medicine

\section{References}

1 Fenech M, El-Sohemy A, Cahill L, Ferguson LR, French TC, et al. (2011) Nutrigenetics and nutrigenomics: viewpoints on the current status and applications in nutrition research and practice. J Nutrigenet Nutrigenomics 4: 69-89.

2 Ordovas JM (2004) Nutrigenetics and Nutrigenomics. World Rev Nutr Diet 93.

3 Farhud DD, Zarif Yeganeh M (2010) Nutrigenomics and Nutrigenetics. Iran J Public Health 39: 1-14.

4 Martins IJ (2015) Unhealthy nutrigenomic diets accelerate nafld and adiposity in global communities. J Mol Genet Med 9: 1-11.

5 Martins IJ (2013) Increased Risk for Obesity and Diabetes with Neurodegeneration in Developing Countries. J Mole Genetic Medicine 1: 1-8.

6 Wang G, Walker SO, Hong X, Bartell TR, Wang X, et al. (2013) Epigenetics and early life origins of chronic noncommunicable diseases. J Adolesc Health 52: S14-S21.

7 Smith R, Mill J (2011) Epigenetics and chronic diseases: an overview. Epigenetic Aspects of Chronic Diseases pp: 1-20.

8 Martins IJ (2016) Anti-aging genes improve appetite regulation and reverse cell senescence and apoptosis in global populations. Adv Aging Res 5: 9-26.

9 Martins IJ (2017) Defective Inter-play between adipose tissue and immune system induces non-alcoholic fatty liver disease. Updates Nutr Disorders 1: 1-5.

10 Logan RW, Sarkar DK (2012) Circadian nature of immune function. Mol Cell Endocrinol 349: 82-90. with relevance to immune disturbances and mitophagy $[9,60]$ in diabetes and MODS (Figure 3). Anxiety, stress and heat/cold stress may induce heat shock protein-mitophagy $[9,60,61,63]$ relevant to brain disease. Sirt 1 inhibitors $[162,163]$ may interfere with dietary regulation of immune responses and accelerated autoimmune disease relevant to chronic disease and MODS.

\section{Conclusion}

Global chronic diseases involve cellular immune alterations that lead to mitophagy in various tissues. High calorie diets are involved with transcriptional dysregulation and defective hepatic xenobiotic associated with immunometabolism disorders in genetic medicine. Nutritional regulation of Sirt 1 is essential to maintain the interplay between NO, glucose homeostasis, immune system and various nuclear receptors, transcription factors/signalling factors and miRNA involved in epigenetics with relevance to human diabetes. Bacterial LPS induced Sirt 1 repression in Type 3/Type 2 diabetes induce NAFLD with increased xenobiotic levels linked to the development of MODS and global chronic disease in the developing world.

\section{Acknowledgements}

This work was supported by grants from Edith Cowan University, the McCusker Alzheimer's Research Foundation and the National Health and Medical Research Council.

11 Mavroudis PD, Scheff JD, Calvano SE, Androulakis IP (2013) Systems biology of circadian-immune interactions. J Innate Immun 5: 153-62.

12 Carcillo JA, Podd B, Aneja R, Weiss SL, Hall MW, et al. (2017) Pathophysiology of pediatric multiple organ dysfunction syndrome. Pediatr Crit Care Med 18: S32-S45.

13 Murray MJ, Coursin DB (1993) Multiple organ dysfunction syndrome. Yale J Biol Med 66: 501-510.

14 Ramírez M (2013) Multiple organ dysfunction syndrome. Curr Probl Pediatr Adolesc Health Care 43: 273-277.

15 Martins IJ (2016) Early diagnosis of neuron mitochondrial dysfunction may reverse global metabolic and neurodegenerative disease. GJMR 2: 1-8.

16 Martins IJ (2017) Drug-drug interactions with relevance to drug induced mitochondrial toxicity and accelerated global chronic diseases. ECPT 3: 18-21.

17 Matsushima S, Sadoshima J (2015) The role of sirtuins in cardiac disease. Am J Physiol Heart Circ Physiol 309: H1375-H1389.

18 Guan Y, Hao CM (2016) SIRT1 and kidney function. Kidney Dis (Basel) 1: 258-265.

19 Hui X, Zhang M, Gu P, Li K, Gao Y, et al. (2017) Adipocyte SIRT1 controls systemic insulin sensitivity by modulating macrophages in adipose tissue. EMBO Rep 18: 645-657.

20 Mariani S, Fiore D, Basciani S, Persichetti A, Contini S, et al. (2015) Plasma levels of SIRT1 associate with non-alcoholic fatty liver disease in obese patients. Endocrine 49: 711-716.

21 Nassir F, Ibdah JA (2016) Sirtuins and nonalcoholic fatty liver disease. World J Gastroenterol 22: 10084-10092. 
22 Colak Y, Yesil A, Mutlu HH, Caklili OT, Ulasoglu C, et al. (2014) A potential treatment of non-alcoholic fatty liver disease with SIRT1 activators. J Gastrointestin Liver Dis 23: 311-319.

23 You M, Jogasuria A, Taylor C, Wu J (2015) Sirtuin 1 signaling and alcoholic fatty liver disease. Hepatobiliary Surg Nutr 4: 88-100.

24 Hall JA, Dominy JE, Lee Y, Puigserver P (2013) The Sirtuin family's role in aging and age-associated pathologies. J Clin Invest 123: 973-979.

25 Conti V, Corbi G, Manzo V, Pelaia G, Filippelli A, et al. (2015) Sirtuin 1 and aging theory for chronic obstructive pulmonary disease. Anal Cell Pathol (Amst) 2015: 897327.

26 Dixon J, Lane K, Macphee I, Philips B (2014) Xenobiotic metabolism: the effect of acute kidney injury on non-renal drug clearance and hepatic drug metabolism. Int J Mol Sci 15: 2538-2553.

27 Yanagisawa S, Papaioannou Al, Papaporfyriou A, Baker J, Vuppusetty C, et al. (2017) Decreased serum sirtuin-1 in chronic obstructive pulmonary disease. Chest S0012-3692: 30921-30922.

28 Chang HC, Guarente L (2014) SIRT1 and other sirtuins in metabolism. Trends Endocrinol Metab 25: 138-145.

29 Hagenbuchner J, Ausserlechner MJ (2013) Mitochondria and FOXO3: Breath or die. Front Physiol 4: 147.

30 Cheng Z, Guo S, Copps K, Dong X, Kollipara R, et al. (2009) Foxo1 integrates insulin signaling with mitochondrial function in the liver. Nat Med 15: 1307-1311.

31 Orsini F, Migliaccio E, Moroni M, Contursi C, Raker VA, et al. (2004) The life span determinant p66Shc localizes to mitochondria where it associates with mitochondrial heat shock protein 70 and regulates trans-membrane potential. J Biol Chem 279: 25689-25695.

32 Trinei M, Migliaccio E, Bernardi P, Paolucci F, Pelicci P, et al. (2013) p66Shc, mitochondria, and the generation of reactive oxygen species. Methods Enzymol 528: 99-110.

33 Munekata K, Sakamoto K (2009) Fork head transcription factor Foxo1 is essential for adipocyte differentiation. In Vitro Cell Dev Biol Anim 45: 642-651.

34 Nakae J, Kitamura T, Kitamura Y, Biggs WH, Arden KC, et al. (2003) The fork head transcription factor Foxo1 regulates adipocyte differentiation. Dev Cell 4: 119-129.

35 Razzaque MS (2012) The role of Klotho in energy metabolism. Nat Rev Endocrinol 8: 579-587.

36 Chihara Y, Rakugi H, Ishikawa K, Ikushima M, Maekawa Y, et al. (2006) Klotho protein promotes adipocyte differentiation. Endocrinology 147: 3835-3842.

37 Berniakovich I, Trinei M, Stendardo M, Migliaccio E, Minucci S, et al. (2008) p66Shc-generated oxidative signal promotes fat accumulation. J Biol Chem 283: 34283-34293.

38 Ciciliot S, Albiero M, Menegazzo L, Poncina N, Scattolini V, et al. (2015) p66Shc deletion or deficiency protects from obesity but not metabolic dysfunction in mice and humans. Diabetologia 58: 23522360.

39 Amaral JD, Xavier JM, Steer CJ, Rodrigues CM (2010) The role of p53 in apoptosis. Discov Med 9: 145-52.

40 Tucci $P$ (2012) Caloric restriction: is mammalian life extension linked to p53? Aging (Albany NY) 4: 525-534.

41 Rodier F, Campisi J, Bhaumik D (2007) Two faces of p53: aging and tumor suppression. Nucleic Acids Res 35: 7475-7484.
42 Rufini A, Tucci P, Celardo I, Melino G (2013) Senescence and aging: the critical roles of p53. Oncogene 32: 5129-5143.

43 Martins IJ, Creegan R (2014) Links between insulin resistance, lipoprotein metabolism and amyloidosis in Alzheimer's disease. Health 6: 1549-1579.

44 Herskovits AZ, Guarente L (2014) SIRT1 in neurodevelopment and brain senescence. Neuron 81: 471-483.

45 Duan W (2013) Sirtuins: from metabolic regulation to brain aging. Front Aging Neurosci 5: 36

46 Martins IJ (2015) Nutritional and genotoxic stress contributes to diabetes and neurodegenerative diseases such as parkinson's and alzheimer's diseases. Frontiers in Clinical Drug Research-CNS and Neurological Disorders 35: 158-192.

47 Choi GE, Mostoslavsky R (2014) Sirtuins, Metabolism, and DNA repair. Curr Opin Genet Dev 0: 24-32.

48 Peng L, Yuan Z, Li Y, Ling H, Izumi V, et al. (2015) Ubiquitinated sirtuin 1 (SIRT1) function is modulated during DNA damage-induced cell death and survival. J Biol Chem 290: 8904-89012.

49 Tang BL (2016) Sirt1 and the mitochondria. Mol Cells 39: 87-95.

50 Rey G, Reddy AB (2013) Protein acetylation links the circadian clock to mitochondrial function. Proc Natl Acad Sci USA 110: 3210-3211.

51 Voloboueva LA, Suh SW, Swanson RA, Giffard RG (2007) Inhibition of mitochondrial function in astrocytes: implications for neuroprotection. J Neurochem 102: 1383-1394.

52 Koczor CA, White RC, Zhao P, Zhu L, Fields E, et al. (2012) p53 and Mitochondrial DNA, Their Role in Mitochondrial Homeostasis and Toxicity of Antiretrovirals. Am J Pathol 180: 2276-2283.

53 Park JH, Zhuang J, Li J, Hwang PM (2016) p53 as guardian of the mitochondrial genome. FEBS Lett 590: 924-934.

54 Sheng ZH, Cai Q (2012) Mitochondrial transport in neurons: impact on synaptic homeostasis and neurodegeneration. Nat Rev Neurosci 13: 77-93.

55 Sheng ZH (2014) Mitochondrial trafficking and anchoring in neurons: New insight and implications. J Cell Biol 204: 1087-1098.

56 Ben-Shachar D, Laifenfeld D (2004) Mitochondria, synaptic plasticity, and schizophrenia. Int Rev Neurobiol 59: 273-296.

$57 \mathrm{Hu} \mathrm{F}$, Liu F (2011) Mitochondrial stress: a bridge between mitochondrial dysfunction and metabolic diseases. Cell Signal 23: 1528-1533.

58 Todorova V, Blokland A (2017) Mitochondria and synaptic plasticity in the mature and aging nervous system. Curr Neuropharmacol 15: 166-173.

59 Bonda DJ, Lee HG, Camins A, Pallàs M, Casadesus G, et al (2011) The critical role of the sirtuin pathway in aging and alzheimer disease: mechanistic and therapeutic considerations. Lancet Neurol 10: 275-279.

60 Martins IJ (2017) Calorie sensitive anti-aging gene regulates hepatic amyloid beta clearance in diabetes and neurodegenerative diseases". EC Nutrition ECO.01 : 30-32.

61 Martins IJ (2017) Regulation of Core Body Temperature and the Immune System Determines Species Longevity. Curr Updates Gerontol 1: 6.1

62 Martins IJ (2016) Heat shock gene Sirtuin 1 regulates post-prandial lipid metabolism with relevance to nutrition and appetite regulation in diabetes. Int J Diab Clin Diagn 3: 20. 
63 Martins IJ (2016) Type 3 diabetes with links to NAFLD and other chronic diseases in the western world. Int J Diab Met Disord 1: 1-5.

64 Martins IJ (2017) Heat shock gene dysregulation and inactivation of drug therapy. ECPT 1: 13-15.

65 Martins IJ (2016) Geriatric medicine and heat shock gene therapy in global populations. Curr Updates Gerontol 1: 1-5.

66 Liang F, Kume S, Koya D (2009) SIRT1 and insulin resistance. Nat Rev Endocrinol 5: 367-373.

67 Zmrzljak UP, Rozman D (2012) Circadian regulation of the hepatic endobiotic and xenobitoic detoxification pathways: the time matters. Chem Res Toxicol 25: 811-824

68 Palacios JA, Herranz D, De Bonis ML, Velasco S, Serrano M, et al. (2010) SIRT1 contributes to telomere maintenance and augments global homologous recombination. J Cell Biol 191: 1299-1313.

69 Moore KJ (2013) microRNAs: small regulators with a big impact on lipid metabolism. J Lipid Res 54: 1159-1160.

70 Mercado C, Eades G, Zhou Q (2013) MicroRNAs: a new class of master regulators of adipogenesis. Human Genet Embryol 3: 108.

71 Xie H, Sun L, Lodish HF (2009) Targeting microRNAs in obesity. Expert Opin Ther Targets 13: 1227-1238.

72 Yamakuchi M, Ferlito M, Lowenstein CJ (2008) miR-34a repression of SIRT1 regulates apoptosis. Proc Natl Acad Sci U S A 105: 1342113426.

73 Lee J, Kemper JK (2010) Controlling SIRT1 expression by microRNAs in health and metabolic disease. Aging (Albany NY) 2: 527-534.

74 Miyazaki Y, Li R, Rezk A, Misirliyan H, Moore C, et al. (2014) A novel microRNA-132-surtuin-1 axis underlies aberrant B-cell cytokine regulation in patients with relapsing-remitting multiple sclerosis. PLOS ONE 9: e105421.

75 Sen N, Satija YK, Das S (2011) PGC-1 $\alpha$, a key modulator of p53, promotes cell survival upon metabolic stress. Mol Cell 44: 621-634.

76 Aquilano K, Baldelli S, Pagliei B, Cannata SM, Rotilio G, et al. (2013) p53 Orchestrates the PGC-1 $\alpha$-Mediated Antioxidant Response Upon Mild Redox and Metabolic Imbalance. Antioxid Redox Signal 18: 386-399.

77 Salminen A, Kaarniranta K, Kauppinen A (2013) crosstalk between oxidative stress and SIRT1: impact on the aging process. Int J Mol Sci 14: 3834-3859.

78 Caito S, Rajendrasozhan, S, Cook S, Chung S, Yao HW, et al. (2010) SIRT1 Is a redox-sensitive deacetylase that is post-translationally modified by oxidants and carbonyl stress. FASEB J 24: 3145-3159.

79 Das S, Misra B, Roul L, Minz NT, Pattnaik M, et al. (2009) Insulin resistance and beta cell function as prognostic indicator in multiorgan dysfunction syndrome. Metab Syndr Relat Disord 7: 47-51.

80 Das S, Misra B (2011) insulin resistance as prognostic indicator in multi organ dysfunction Syndrome. Medicine Update 420-426.

81 Martins IJ (2016) Diet and Nutrition reverse type 3 diabetes and accelerated aging linked to global chronic diseases. J Diab Res Ther 2: 1-6.

82 Martins IJ (2015) Diabetes and organ dysfunction in the developing and developed. GJMR 15: 15-21.

83 Martins IJ (2016) The role of clinical proteomics, lipidomics, and genomics in the diagnosis of alzheimer's disease. proteomes 4: 1-19.

84 Liang Q, Zhong L, Zhang J, Wang Y, Bornstein SR, et al. (2014) FGF21 maintains glucose homeostasis by mediating the cross talk between liver and brain during prolonged fasting. Diabetes 63: 4064-4075.

85 Martins IJ (2015) Nutritional diets accelerate amyloid beta metabolism and prevent the induction of chronic diseases and Alzheimer's disease. Photon Ebooks pp: 1-48.

86 Martins IJ (2014) The global obesity epidemic is related to stroke, dementia and alzheimer's disease. JSM Alzheimer's Dis Related Dementia 1: 1010.

87 Martins IJ (2017) Apelinergic system defects with relevance to mental disorders in diabetes. World J Psychiatry Ment Health Res 1: 1001.

88 Tilg H, Moschen AR (2006) Adipocytokines: mediators linking adipose tissue, inflammation and immunity. Nat Rev Immunol 6: 772-783.

89 Kamada Y, Takehara T, Hayashi N (2008) Adipocytokines and liverdisease. J Gastroenterol 43: 811-822.

90 Bertolani C, Marra F (2010) Role of adipocytokines in hepatic fibrosis. Curr Pharm Des 16: 1929-1940.

91 Ikejima K, Okumura K, Kon K, Takei Y, Sato N (2007) Role of adipocytokines in hepatic fibrogenesis. J Gastroenterol Hepatol 22: S87-S92.

92 Tilg H (2010) Adipocytokines in nonalcoholic fatty liver disease: keyplayers regulating steatosis, inflammation and fibrosis. Curr Pharm Des 16: 1893-1895.

93 Zelber-Sagi S, Ratziu V, Zvibel I, Goldiner I, Blendis L, et al. (2012) Theassociation between adipocytokines and biomarkers for nonalcoholic fatty liver disease-induced liver injury: a study in the general population. Eur J Gastroenterol Hepatol 24: 262-269.

94 Polyzos SA, Kountouras J, Zavos C (2009) Nonalcoholic fatty liver disease: the pathogenetic roles of insulin resistance and adipocytokines. Curr Mol Med 9: 299-314.

95 Yoshizaki T, Schenk S, Imamura T, Babendure JL, Sonoda N, et al (2010) SIRT1 inhibits inflammatory pathways in macrophages and modulates insulin sensitivity. Am J Physiol Endocrinol Metab 298: E419-E428.

96 Gillum MP, Kotas ME, Erion DM, Kursawe R, Chatterjee P, et al. (2011) SirT1 regulates adipose tissue inflammation. Diabetes 60: 32353245.

97 Kotas ME, Gorecki MC, Gillum MP (2013) Sirtuin-1 is a nutrientdependent modulator of inflammation. Adipocyte 2: 113-118.

98 Qiao L, Shao J (2006) SIRT1 regulates adiponectin gene expression through Foxo1-C/enhancer-binding protein alpha transcriptional complex. J Biol Chem 281: 39915-39924.

99 Xiong S, Salazar G, Patrushev N, Alexander RW (2011) FoxO1 mediates an autofeedback loop regulating SIRT1 expression. J Biol Chem 286: 5289-5299

100 Jin Q, Zhang F, Yan T, Liu Z, Chunxi W, et al. (2010) C/EBP_regulates SIRT1 expression during adipogenesis. Cell Res 20: 470-479.

101 Chihara Y, Rakugi, Ishikawa K, Ikushima M, Maekawa Y, et al (2006) Klotho protein promotes adipocyte differentiation. Endocrinology 147: 3835-3842.

102 Oka S, Alcendor R, Zhai, P, Park JY, Shao D, et al. (2011) PPAR_-Sirt1 complex mediates cardiac hypertrophy and failure through suppression of the ERR transcriptional pathway. Cell Metab 14: 598-611.

103 Nie Y, Wong C (2009) Suppressing the activity of ERRalpha in 3T3L1 adipocytes reduces mitochondrial biogenesis but enhances glycolysis and basal glucose uptake. J Cell Mol Med 13: 3051-3060. 
104 Chau MD, Gao J, Yang Q, Wu Z, Gromada J (2010) Fibroblast growth factor 21 regulates energy metabolism by activating the AMPKSIRT1-PGC-1alpha pathway. PNAS 107: 12553-12558.

105 Li Y, Wong K, Giles A, Jiang J, Lee JW, et al. (2014) Hepatic SIRT1 attenuates hepatic steatosis and controls energy balance in mice by inducing fibroblast growth factor 21. Gastroenterology 146: 539-49.e7.

106 Suzuki M, Uehara Y, Motomura-Matsuzaka K, Oki J, Koyama Y, et al. (2008) betaKlotho is required for fibroblast growth factor (FGF) 21 signaling through FGF receptor (FGFR) 1c and FGFR3c. Mol Endocrinol 22: 1006-1014.

107 Yie J, Wang W, Deng L, Tam LT, Stevens J, et al. (2012) Understanding the physical interactions in the FGF21/FGFR/-Klotho complex: Structural requirements and implications in FGF21 signaling. Chem Biol Drug Des 79: 398-410.

108 Wolf I, Levanon-Cohen S, Bose S, Ligumsky H, Sredni B, et al. (2008) Klotho: A tumor suppressor and a modulator of the IGF-1 and FGF pathways in human breast cancer. Oncogene 27: 7094-7105.

109 Picard F, Kurtev M, Chung N, Topark-Ngarm A, Senawong T, et al. (2004) Sirt1 promotes fat mobilization in white adipocytes by repressing PPAR-gamma. Nature 429: 771-776.

110 Fan W, Imamura T, Sonoda N, Sears DD, Patsouris D, et al. (2009) FOXO1 transrepresses peroxisome proliferator-activated receptorgamma transactivation, coordinating an insulin-induced feed-forward response in adipocytes. J Biol Chem 284: 12188-1219.

111 Chakrabarti P, English T, Karki S, Qiang L, Tao R, et al. (2011) SIRT1controls lipolysis in adipocytes via FOXO1-mediated expression of ATGL. J Lipid Res 52: 1693-1701.

112 Luu L, Dai FF, Prentice KJ, Huang X, Hardy AB, et al. (2013) The loss of Sirt1 in mouse pancreatic beta cells impairs insulin secretion by disrupting glucose sensing. Diabetologia 56: 2010-2020.

113 Dantas KC, Bydlowski SP, Novak EM (2006) Study of activity transcription factors C/EBP in region-53 to -33 of promoter apolipoprotein B gene. Rev Bras Ciências Farm Braz J Pharm Sci 42: 405-411.

114 Ding N, Hah N, Yu RT, Sherman MH, Benner C, et al. (2015) BRD4 is a novel therapeutic target for liver fibrosis. Proc Natl Acad Sci USA 112: $15713-15718$

115 Yoshino J, Klein S (2013) A novel link between circadian clocks and adipose tissue energy metabolism. Diabetes 62: 2175-2177.

116 Sun H, Huang FF, Qu S (2015) Melatonin: a potential intervention for hepatic steatosis. Lipids Health Dis 14: 75.

117 Wang X, Michael D, de Murcia G, Oren M (2002) p53 Activation by Nitric Oxide Involves Down-regulation of Mdm2. J Biol Chem 277: 15697-15702.

118 Forrester K, Ambs S, Lupold SE, Kapust RB, Spillare EA, et al. (1996) Nitric oxide-induced p53 accumulation and regulation of inducible nitric oxide synthase expression by wild-type p53. Proc Natl Acad Sci USA 93: 2442-2447.

119 Messmer UK, Brüne B (1996) Nitric oxide-induced apoptosis: p53dependent and p53-independent signalling pathways. Biochem J 319: 299-305.

120 Multhoff G (2002) Activation of natural killer cells by heat shock protein 70. Int J Hyperthermia 18: 576-585.

121 Donato AJ, Magerko KA, Lawson BR, Durrant JR, Lesniewski LA, et al. (2011) SIRT-1 and vascular endothelial dysfunction with ageing in mice and humans. J Physiol 589: 4545-4554.
122 Ota H, Eto M, Kano MR, Kahyo T, Setou M, et al. (2010) Induction of endothelial nitric oxide synthase, SIRT1, and catalase by statins inhibits endothelial senescence through the Akt pathway. Arterioscler Thromb Vasc Biol 30: 2205-2211.

123 Kilic U, Gok O, Elibol-Can B, Uysal O, Bacaksiz A (2015) Efficacy of statins on sirtuin 1 and endothelial nitric oxide synthase expression: the role of sirtuin 1 gene variants in human coronary atherosclerosis. Clin Exp Pharmacol Physiol 42: 321-330.

124 Liu J, Zhang C, Zhao Y, Feng Z (2017) MicroRNA Control of p53. J Cell Biochem 118: 7-14.

125 Kalinowski L, Janaszak-Jasiecka A, Siekierzycka A, Bartoszewska S, Woźniak M, et al. (2016) Posttranscriptional and transcriptional regulation of endothelial nitric-oxide synthase during hypoxia: the role of microRNAs. Cell Mol Biol Lett 21: 16.

126 Lee SK, Kim HS, Song YJ, Joo HK, Lee JY, et al. (2008) Alteration of p66shc is associated with endothelial dysfunction in the abdominal aortic coarctation of rats. FEBS Lett 582: 2561-2566.

127 Shi Y, Lüscher TF, Camici GG (2014) Dual role of endothelial nitric oxide synthase in oxidized LDL-induced, p66Shc-mediated oxidative stress in cultured human endothelial cells. PLoS ONE 9: e107787.

128 Magenta A, Greco S, Capogrossi MC, Gaetano C, Martelli F (2014) Nitric oxide, oxidative stress, and p66Shc interplay in diabetic endothelial dysfunction. Biomed Res Int 2014: 193095.

129 Chung CP, Chang YC, Ding Y, Lim K, Liu Q, et al. (2017) $\alpha$-Klotho expression determines nitric oxide synthesis in response to FGF-23 in human aortic endothelial cells. PLoS ONE 12: e0176817.

130 Nakamura T, Saito Y, Ohyama Y, Masuda H, Sumino H, et al. (2002) Production of nitric oxide, but not prostacyclin, is reduced in klotho mice. Jpn J Pharmacol 89:149-156.

131 Saito Y, Kurabayashi M, Nakamura T, Nagai R (2006) [Klotho gene and endothelial function]. Nihon Ronen Igakkai Zasshi 43: 342-344.

132 Borniquel S, García-Quintáns N, Valle I, Olmos Y, Wild B, et al. (2010) Inactivation of Foxo3a and subsequent downregulation of PGC-1 alpha mediate nitric oxide-induced endothelial cell migration. Mol Cell Biol 30: 4035-4044.

133 Hughes KJ, Meares GP, Hansen PA, Corbett JA (2011) FoxO1 and SIRT1 regulate beta-cell responses to nitric oxide. J Biol Chem 286: 8338-8348.

134 Geng T, Li P, Yin X, Yan Z (2011) PGC-1 $\alpha$ promotes nitric oxide antioxidant defenses and inhibits FOXO signaling against cardiac cachexia in mice. Am J Pathol 178: 1738-1748.

135 Borniquel S, Valle I, Cadenas S, Lamas S, Monsalve M (2006) Nitric oxide regulates mitochondrial oxidative stress protection via the transcriptional coactivator PGC-1alpha. FASEB J 20: 1889-1891.

136 Abd-Elrahman KS, El-Gowelli HM, Saad El, Abdel-Galil AG, El-Mas MM (2010) Role of PPAR gamma/nitric oxide synthase signaling in the cyclosporine-induced attenuation of endothelium-dependent renovascular vasodilation. J Cardiovasc Pharmacol 56: 195-202.

137 Li M, Pascual G, Glass CK (2000) Peroxisome proliferator-activated receptor gamma-dependent repression of the inducible nitric oxide synthase gene. Mol Cell Biol 20: 4699-4707.

138 Watts GF, Staels B (2004) Regulation of endothelial nitric oxide synthase by PPAR agonists: molecular and clinical perspectives. Arterioscler Thromb Vasc Biol 24: 619-621

139 Zhao JF, Shyue SK, Lin SJ, Wei J, Lee TS (2014) Excess nitric oxide impairs LXR( $\alpha$ )-ABCA1-dependent cholesterol efflux in macrophage foam cells. J Cell Physiol 229: 117-125. 
140 Secor McVoy JR, Oughli HA, Oh U (2015) Liver X receptordependent inhibition of microglial nitric oxide synthase 2 . J Neuroinflammation 12: 27.

141 Lira VA, Brown DL, Lira AK, Kavazis AN, Soltow QA, et al. (2010) Nitric oxide and AMPK cooperatively regulate PGC-1 $\alpha$ in skeletal muscle cells. J Physiol 588: 3551-3566.

142 Deshmukh AS, Long YC, de Castro Barbosa T, Karlsson HKR (2010) Nitric oxide increases cyclic GMP levels, AMP-activated protein kinase (AMPK) $\alpha 1$-specific activity and glucose transport in human skeletal muscle. Diabetologia 53: 1142-1150.

143 Xu Q, Hu Y, Kleindienst R, Wick G (1997) Nitric oxide induces heatshock protein 70 expression in vascular smooth muscle cells via activation of heat shock factor 1. J Clin Invest 100: 1089-1097.

144 Feinstein DL, Galea E, Aquino DA, Li GC, Xu H, et al. (1996) Heat shock protein 70 suppresses astroglial-inducible nitric-oxide synthase expression by decreasing NFkappaB activation. J Biol Chem 271: 17724-17732.

145 Steiner AA, Branco LGS (2001) Nitric oxide in the regulation of body temperature and fever J Thermal Biology 26: 325-330.

146 Yang WW, Krukoff TL (2000) Nitric oxide regulates body temperature, neuronal activation and interleukin-1 beta gene expression in the hypothalamic paraventricular nucleus in response to immune stress. Neuropharmacology 39: 2075-2089.

147 Ragoobirsingh D, McGrowder D, Dasgupta T, Brown P (2004) The effect of nitric oxide on glucose metabolism. Mol Cell Biochem 263 : 29-34.

148 Cosentino F, Hishikawa K, Katusic ZS, Lüscher TF (1997) High glucose increases nitric oxide synthase expression and superoxide anion generation in human aortic endothelial cells. Circulation 96: 25-28.

149 Handy DE, Loscalzo J (2017) Epigenetics and the regulation of nitric oxide. In: Bryan N, Loscalzo J (eds.) Nitrite and nitrate in human health and disease. Nutrition and Health. Humana Press, Cham, pp: 33-52.

150 Vasudevan D, Bovee RC, Thomas DD (2016) Nitric oxide, the new architect of epigenetic landscapes. Nitric Oxide 59: 54-62.

151 Wink DA, Osawa Y, Darbyshire JF, Jones CR, Eshenaur SC, et al. (1993) Inhibition of cytochromes P450 by nitric oxide and a nitric oxide-releasing agent. Arch Biochem Biophys 300: 115-123.
152 Minamiyama Y, Takemura S, Imaoka S, Funae $Y$, Tanimoto $Y$, et al. (1997) Irreversible inhibition of cytochrome P450 by nitric oxide. J Pharmacol Exp Ther 283: 1479-1485.

153 Keserü GM, Volk B, Balogh GT (2000) Cytochrome P450 catalyzed nitric oxide synthesis: a theoretical study. J Biomol Struct Dyn 17: 759-767

154 Wang X, Fang X, Zhou J, Chen Z, Zhao B, et al. (2013) Shear stress activation of nuclear receptor PXR in endothelial detoxification. Proc Natl Acad Sci U S A 110: 13174-13179.

155 Toell A, Kröncke KD, Kleinert H, Carlberg C (2002) Orphan nuclear receptor binding site in the human inducible nitric oxide synthase promoter mediates responsiveness to steroid and xenobiotic ligands. J Cell Biochem 85: 72-82.

156 Luster MI, Ackermann MF, Germolec DR, Rosenthal GJ (1989) Perturbations of the immune system by xenobiotics. Environ Health Perspect 81: 157-162.

157 Wang S, Lei T, Zhang K, Zhao W, Fang L, et al. (2014) Xenobiotic pregnane $X$ receptor (PXR) regulates innate immunity via activation of NLRP3 inflammasome in vascular endothelial cells. J Biol Chem 289: 30075-30081.

158 Smith RP, Wilcox DE (1994) Toxicology of selected nitric oxidedonating xenobiotics, with particular reference to azide. Crit Rev Toxicol 24: 355-377.

159 Charles A (1999) Nitric oxide pumps up calcium signalling. Nat Cell Biol 1: E193-E195.

160 Van Hove CE, Van der Donckt C, Herman AG, Bult H, Fransen P (2009) Vasodilator efficacy of nitric oxide depends on mechanisms of intracellular calcium mobilization in mouse aortic smooth muscle cells. Br J Pharmacol 158: 920-930.

161 Takeuchi K, Watanabe H, Tran QK, Ozeki M, Sumi D, et al. (2004) Nitric oxide: inhibitory effects on endothelial cell calcium signaling, prostaglandin 12 production and nitric oxide synthase expression. Cardiovasc Res 62: 194-201.

162 Martins IJ (2017) Nutrition therapy regulates caffeine metabolism with relevance to NAFLD and induction of type 3 diabetes. Diabetes Metab Disord 4: 019.

163 Martins IJ (2017) The future of genomic medicine involves the maintenance of sirtuin 1 in global populations. Int J Mol Biol 2: 00013. 